\title{
Modelling the Absorption of Metformin with Patients Post Gastric Bypass Surgery
}

May Almukainzi ${ }^{1 *}$, Viera Lukacova ${ }^{2}$ and Raimar Löbenberg ${ }^{1}$

${ }^{1}$ Katz Group-Rexall Centre for Pharmacy \& Health Research, University of Alberta, Edmonton, Canada

${ }^{2}$ Simulations Plus, Inc. Lancaster, USA

\begin{abstract}
Purpose: Gastric bypass surgery in obesity shortens the length of the small intestine, which can have a significant impact on drug absorption. Literature reports that the observed drug absorption patterns after gastric bypass surgery are sometimes unexpected. One report states that the absorption of Metformin was higher after gastric bypass surgery. The purpose of this study was to investigate the mechanistic background of the reported data using Advanced Compartmental Absorption and Transit (ACAT ${ }^{\mathrm{TM}}$ ) model and apply it to patient data with post gastric bypass surgery.
\end{abstract}

Methods: GastroPlus ${ }^{\mathrm{TM}} 8$ (Simulations Plus, Inc.) was used to develop a model that describes the observed absorption of an immediate release (IR) metformin tablet in healthy subjects. The data was taken from a published article that compared the absorption of metformin between a control group and post gastric bypass surgery patients. The model was fitted against the data for the control group and then used to predict the drug absorption in post gastric bypass surgery patients by changing the related GI parameters. All assumptions to explain the observed data, suggested in the literature, were tested by changing the appropriate parameters in the software.

Results: As theoretically expected, GastroPlus ${ }^{\mathrm{TM}}$ underestimated the absorption of metformin in patients with post gastric bypass surgery due to the lesser absorption area. The increase in the pore size and porosity of the last part of the small intestine successfully predict the observed PK parameters. Changing other speculated parameters failed to predict the observed absorption pattern.

Conclusion: The simulation of the observed absorption of metformin in post gastric bypass surgery patient was found where there was a change in the metformin gut paracellular permeability. This indicates that the gut must have undergone an adoption process to compensate for the loss of parts of the small intestine. The insights gained by this study can be used to predict the absorption of other drugs that have similar physiochemical properties like metformin. Computer simulations can be used to simulate the impact and mechanistic background of disease or other physiological changes like surgery on drug absorption.

\section{Introduction}

Phase one clinical drug development and bioequivalence studies are performed using healthy volunteers. However, some conditions and diseases can change the physiology in a patient. These changes can have a significant impact on the ability of a dosage form to deliver the desired drug dose. One of these conditions that cause changes in physiological

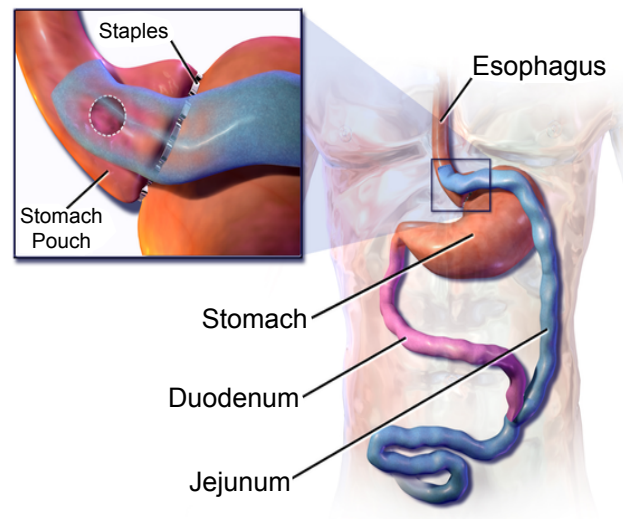

\section{Roux-En-Y}

Figure 1: Roux-en-Y gastric bypass (RYGB) properties is weight loss surgery. Gastric bypass surgery in an obesity treatment shortens the length of the small intestine, which can have a major impact on drug absorption.

Obesity Surgery is a treatment procedure that aims to decrease the body weight in obese patients by, for example, shortening the intestine and/or shrinking the stomach. The operations are effective treatment options for patients with body mass index BMI $\geq 30 \mathrm{~kg} / \mathrm{m}^{2}[1]$. In 2008 , almost 350,000 bariatric procedures were performed around the world and 220.500 procedures were performed in US/Canada alone [2]. There are many types of obesity surgery: purely restrictive (gastric banding, gastroplasty), primarily malabsorptive (jejunoileal bypass), and combined restrictive and malabsorptive (gastric bypass RouxEn-Y; and biliopancreatic diversion with Duodenal Switch. Roux-en-Y

*Corresponding author: May Almukainzi, Faculty of Pharmacy and Pharmaceutical Sciences, Katz Group-Rexall Centre for Pharmacy \& Health Research, University of Alberta, Edmonton, AB, Canada, Tel: +117807293357 E-mail: almukain@ualberta.ca

Received February 13, 2014; Accepted March 27, 2014; Published March 31 2014

Citation: Almukainzi M, Lukacova V, Löbenberg R (2014) Modelling the Absorption of Metformin with Patients Post Gastric Bypass Surgery. J Diabetes Metab 5: 353 doi:10.4172/2155-6156.1000353

Copyright: (c) 2014 Almukainzi M, et al. This is an open-access article distributed under the terms of the Creative Commons Attribution License, which permits unrestricted use, distribution, and reproduction in any medium, provided the original author and source are credited. 
gastric bypass (RYGB) is a popular operation as it claimed to be the most effective and safest procedure to decrease the body weight in obese patients [3] (Figure 1). Currently there are no specific guidelines for adjusting the dose of drugs administered to post gastric bypass surgery patients, and the effect of the surgery on a drugs' bioavailability is not very clear [4]. Literature reports that the observed drug absorption patterns after gastric bypass surgery are sometimes unexpected.

Metformin is one of the most prescribed drugs that used as insulin sensitizer in diabetes type II patients [5]. One report states that the absorption of metformin was higher after gastric bypass surgery [2] The published study compared the absorption of metformin in a 16 non-diabetic post $\geq 3$ months gastric bypass patients and 16 -sex and BMI matched- control subjects, who were administered $1000 \mathrm{mg}$ metformin dose. The study hypothesized that gastric bypass would significantly reduce the amount of absorbed drug in RYGB subjects compared to control subjects [2]. Contrary to their hypothesis, the metformin bioavailability in RYGB subjects was increased [2]. This study has discussed several potential mechanisms that could explain the observation, and concluded by suggesting performing further studies to explain the presented assumption [2]. Understanding the mechanistic reasons behind the observation in drug absorption is essential to avoid unwanted outcomes and might help to address shortfalls in drug delivery. In silico simulations can be used for this purpose as these tools can save time, experiments and, therefore, money.

The importance of modeling disease states is to mimic the true situation and to identify variables that explain the observed data, and this will help in understanding the relationship between these variables and the observations. Physiologically based pharmacokinetic (PBPK) computer models are commercially available which can be used to investigate these variables. GastroPlus ${ }^{\mathrm{TM}}$ is one of these computer programs that used PBPK. GastroPlus ${ }^{\mathrm{TM}}$ includes Advanced Compartmental Absorption and Transit model (ACAT). This model is an extension [6] of the original Compartmental Absorption and Transit (CAT) model which was developed by Yu and Amidon [7], to predict the drug absorption from the Gastrointestinal tract (GIT). ACAT can

\begin{tabular}{|c|c|c|}
\hline Parameter & Input & Reference \\
\hline Dose & 1000 & {$[2]$} \\
\hline Dosage form & immediate release & {$[2]$} \\
\hline Molecular weight & 129.17 & ADMET Predictor 6 \\
\hline LogD (7.4) & -3.37 & {$[28]$} \\
\hline Solubility & $134.87 \mathrm{mg} / \mathrm{mL} @ \mathrm{pH}=12.9$ & ADMET Predictor 6 \\
\hline Permeability & $\begin{array}{c}\mathrm{P}_{\text {app }}, \text { total }=0.05 \times 10^{-5} \mathrm{~cm} / \mathrm{s} \\
\text { Paracellular }=.4467 \times 10^{-4} \mathrm{~cm} / \mathrm{s} \\
\text { Transcellular }=0.0001 \times 10^{-4} \mathrm{~cm} / \mathrm{s}\end{array}$ & $\begin{array}{c}\text { ADMET Predictor } \\
\text { 6Proctor, 2010) }\end{array}$ \\
\hline pKa & $10.17,7.14$ & ADMET Predictor 6 \\
\hline
\end{tabular}

Table 1: Inputs parameters used in control and post gastric bypass in the compound window of GastroPlus ${ }^{\mathrm{TM}}$.

\begin{tabular}{|c|c|c|c|}
\hline Transporter & Location & Transporter kinetics & Reference \\
\hline PMAT & Intestine & $\mathrm{Km}=1.32 \mathrm{mM}$ & {$[13]$} \\
\hline OCT1 & Liver & $\begin{array}{c}\mathrm{Km}=1.47 \mathrm{mM} \\
\text { Vmax }=396 \mathrm{pmol} / \mathrm{min} / \mathrm{mg} \text { protein }\end{array}$ & {$[17]$} \\
\hline OCT2 & Kidney & $\begin{array}{r}\mathrm{Km}=0.99 \mathrm{mM}, \\
\text { Vmax }=1444 \mathrm{pmol} / \mathrm{min} / \mathrm{mg} \text { protein }\end{array}$ & {$[17]$} \\
\hline MATE1 & $\begin{array}{c}\text { Liver and } \\
\text { Kidney }\end{array}$ & $\begin{array}{r}\mathrm{Km}=0.78 \mathrm{mM}, \\
\text { Vmax }=4.46 \mathrm{nmol} / \mathrm{min} / \mathrm{mg} \text { protein }\end{array}$ & {$[16]$} \\
\hline MATE-K2 & Kidney & $\begin{array}{r}\mathrm{Km}=1.98 \mathrm{mM}, \\
\text { Vmax }=1.69 \mathrm{nmol} / \mathrm{min} / \mathrm{mg} \text { protein }\end{array}$ & {$[16]$} \\
\hline
\end{tabular}

Table 2: Inputs parameters used in control and post gastric bypass in the transporter window of GastroPlus ${ }^{\mathrm{TM}}$. be used to predict absorption-based properties from preclinical and in vitro data. Theses module accounts not only for physiological properties in GIT, but also for physicochemical parameters of the compounds, which impact the drug bioavailability and absorption [3].

The purpose of this study was to investigate the mechanistic background of the reported metformin absorption in patients post gastric bypass surgery using GastroPlus ${ }^{\mathrm{TM}}$.

\section{Methods}

\section{Control group}

In order to validate the simulation model, IV data was first used for the simulation to obtain (fit) compartmental PK parameters. The IV data was for healthy individuals receiving a $500 \mathrm{mg}$ dose as IV bolus $[8,9]$. The simulations were performed on a Dell Laptop with Intel core i7 $(2.4 \mathrm{GHz})$ using GastroPlus version 8.5 software (Simulation Plus, Inc., Lancaster, CA). Input parameters required to run the prediction were extracted from literature or predicted from the drug structure using ADMET Predictor ${ }^{\mathrm{rm}}$ version 6 (Simulations Plus, Inc., Lancaster, CA) and are presented in Table 1. The default setting of PBPKof 30 year's human American male module was used. The body weight was changed to $114 \mathrm{~kg}$, which is the average body weight of the subjects in the experimental study. All tissues in the PBPK modules were setting to be limited by their permeability because Metformin has low permeability. Metformin is reported to be a substrate for influx organic cation transporters (OCTs). OCT1 is the first member of the OCTs family, and it is mainly located in the human liver, whereas OCT2 is expressed highly in kidney [10-12] OCT3, is reported to be localized on the apical membrane of human small intestine $[11,12]$. However, OCT3 have low affinity to metformin $[13,14]$. Therefore, OCT3 was not included in the simulation. Recently, studies suggest that metformin is a substrate to a new transporter: Plasma Membrane Monoamine Transporter (PMAT). PMAT is expressed in human small intestine, and play a role in the intestinal uptake of metformin [13]. Studies have also showed that Metformin is substrate for efflux transporters multidrug and toxin extrusions (MATE1 and MATE2-K) $[15,16]$. MATE1 is located in the apical membrane of the liver and kidney, and MATE2 is expressed mainly in the kidney $[16,17]$.

GastroPlus $^{\mathrm{TM}}$ has the option to use and specified the location of such transporters by adding some extra inputs in to the software. The values of the $\mathrm{Km}$ and $V \max$ of transporters extracted from in vitro experimental data in the literatures and used as input in to the software (Table 2). Metformin absorption in the control group was simulated using default human fasted intestinal physiology in GastroPlus. The physiological factors and parameters including the GI transit time, physiological $\mathrm{pH}$, and small intestine is presented in Table 3 .

In the intestine, $90 \%$ of Metformin is absorbed paracellularly [2] Zhimin model [18] in GastroPlus ${ }^{\mathrm{TM}}$ was used to estimate and account for the paracellular permeability mechanism of Metformin. To validate the model, the pharmacokinetics parameters were compared with the experimental data

\section{Post RYGB group}

Once a suitable absorption and pharmacokinetic model was established and evaluated for the control group, the physiology input parameters were changed to mimic the RYGB. These conditions included: gastric volume, $\mathrm{pH}$, small intestine length and small intestine transit time. These inputs were taken from literatures that identified the changes in physiology after RYGB. Surgery of RYGB reduces the 


\begin{tabular}{|c|c|c|c|c|c|c|c|c|}
\hline Compartment & $\mathrm{pH}$ & Transit time (h) & $\begin{array}{l}\text { Volume } \\
(\mathrm{ml})\end{array}$ & Length (cm) & $\begin{array}{l}\text { Radius } \\
\text { (cm) }\end{array}$ & SEF $^{a}$ & $\begin{array}{l}\text { Pore Radius } \\
\text { (A) }\end{array}$ & $\begin{array}{l}\text { Porosity/Pore Length } \\
\left(\mathrm{cm}^{\wedge}-1\right)\end{array}$ \\
\hline Stomach & 1.3 & 0.25 & 50 & 30 & 10 & 1.000 & 2.200 & 2.580 \\
\hline Duodenum & 6 & 0.26 & 48.25 & 15 & 1.60 & 4.235 & 10.41 & 48.64 \\
\hline Jejunum 1 & 6.20 & 0.95 & 175.3 & 62 & 1.50 & 3.949 & 9.6400 & 38.90 \\
\hline Jejunum 2 & 6.40 & 0.76 & 139.9 & 62 & 1.34 & 3.489 & 8.400 & 26.09 \\
\hline Ileum 1 & 6.60 & 0.59 & 108.5 & 62 & 1.18 & 3.029 & 7.160 & 16.46 \\
\hline Ileum 2 & 6.90 & 0.43 & 79.48 & 62 & 1.01 & 2.569 & 5.920 & 9.540 \\
\hline Ileum 3 & 7.40 & 0.31 & 56 & 62 & 0.85 & 2.109 & 4.680 & 4.896 \\
\hline Caecum & 6.40 & 4.50 & 52.92 & 13.75 & 3.50 & 1.790 & 3.920 & 2.915 \\
\hline Ascending colon & 6.80 & 13.50 & 56.98 & 29.02 & 2.50 & 2.480 & 3.500 & 3.220 \\
\hline
\end{tabular}

a - SEF represent Surface area Enhancement Factors which are a measure of absorptive surface area in individual compartments

Table 3: ACAT Model Parameters for the Human fasted physiology.

\begin{tabular}{|c|c|c|c|}
\hline Compartment & SEFa & Pore Radius (A) & Porosity/Pore Length $\left(\mathrm{cm}^{\wedge}-1\right)$ \\
\hline Stomach & 1.000 & 2.200 & 2.580 \\
\hline Duodenum & 4.235 & 10.41 & 48.64 \\
\hline Jejunum 1 & 3.949 & 9.6400 & 38.90 \\
\hline Jejunum 2 & 3.489 & 8.400 & 26.09 \\
\hline Ileum 1 & 6 & 8.1 & 32 \\
\hline Ileum 2 & 5 & 6.90 & 18 \\
\hline Ileum 3 & 4 & 5.680 & 9 \\
\hline Caecum & 1.790 & 3.920 & 2.915 \\
\hline Ascending colon & 2.480 & 3.500 & 3.220 \\
\hline
\end{tabular}

Table 4: The pore size, pore density and the absorptive surface area in post gastric model.

stomach volume by creating a 15 to $20 \mathrm{~mL}$ gastric pouch. The jejunum is divided at 30 to $40 \mathrm{~cm}$ distal to the ligament of Treitz. Then the distal jejunal limb is reconstructed to the new gastric pouch to form the Roux limb. The length of the Roux limb is approximately 75 to $150 \mathrm{~cm}$ in long, depending on the patient's weight $[3,19]$ (Figure1). The main changes that were made in the GIT physiology to build the RYGB physiology in GastroPlus ${ }^{\mathrm{TM}}$ were as the following:

- GI pH: Normal gastric pH in fasted state in human is in the range 1 to 3 [3].The small gastric pouch surface area is decreased in patients after RYGB. As a result, the stomach $\mathrm{pH}$ is expected to increase in these patients $[2,20,21]$. To mimic this change, the $\mathrm{pH}$ was changed from the default 1.3 to 2 in the RYGB physiology model.

- GI Volume: To simulate the smaller gastric pouch, the stomach volume in ACAT model was changed to $30 \mathrm{ml}$

- GI transit time: Literatures reported an acceleration in gastric emptying after gastric bypass $[11,22,23]$;others found that the gastric emptying time after RYGB is reduced [24] and some concluded that these changes are variable [25]. Therefore, no changes were made for the gastric emptying. As discussed above, in the RYGB the intestinal duodenum and jejunum is bypassed [3]. To mimic this condition, the transit times and the length of duodenum and jejunum compartments in ACAT model were set to zero. Data suggest that the transit time of small intestine is increased $[4,24,26]$, Quigley et al. found that the small intestinal transit time is increased by $35 \%$ following $50 \%$ resections of dogs small instinet and by $29 \%$ following $75 \%$ of the resections [27]. Therefore, the transit time of the ileum was increased by $32 \%$ especially that the RYGB resections, to some extent, is variable.

To mechanistically understand the reasons behind the observed data, every assumption that was presented the article [2] was examined by changing the related parameters.
- The first mechanism that was discussed in the article was that RYGB expected to delay the gastric emptying and the increased gastrointestinal transit time may increase the overall absorption of metformin. The article mentioned that this process is working in a manner similar to slow-release formulations of metformin, which remained in the stomach and released drug gradually into the small intestine. To examine this assumption, a modified gastric release formulation model was used to simulate this effect. The modified Gastric Release option allows retaining drug in the stomach and releases it over time.

- The second assumption was that there is an alteration in the transporters. To test this assumption, using GastroplusTM, the expression of the transporters was doubled in the remaining part of small intestine.

- The last assumption was that the small-intestinal undergoes adaptation from villous hyperplasia. To test this assumption, the pore size, pore density and the absorptive surface area were changed to the values given in Table 4 for the remaining part of the small intestine.

\section{Result}

\section{Control group}

Using default Human Physiological Fasted intestinal physiology, GastroPlus estimated the plasma concentration curve very close to observed data with $\mathrm{R}^{2}=0.9$, (Figure 2). The values of $\mathrm{C}_{\max }, \mathrm{T}_{\max }$ and AUC of the predicted data were closely matched to the observed one for the control group (Table 5).

\section{Post gastric bypass}

As expected, the adjustment of intestinal physiology based on simple removal of the bypassed portions of small intestine from the model, underestimate the exposure of metformin in subjects after RYGB. Figure 3 presents the observed and predicted absorption of metformin after RYGB. 
Citation: Almukainzi M, Lukacova V, Löbenberg R (2014) Modelling the Absorption of Metformin with Patients Post Gastric Bypass Surgery. J Diabetes Metab 5: 353 doi:10.4172/2155-6156.1000353

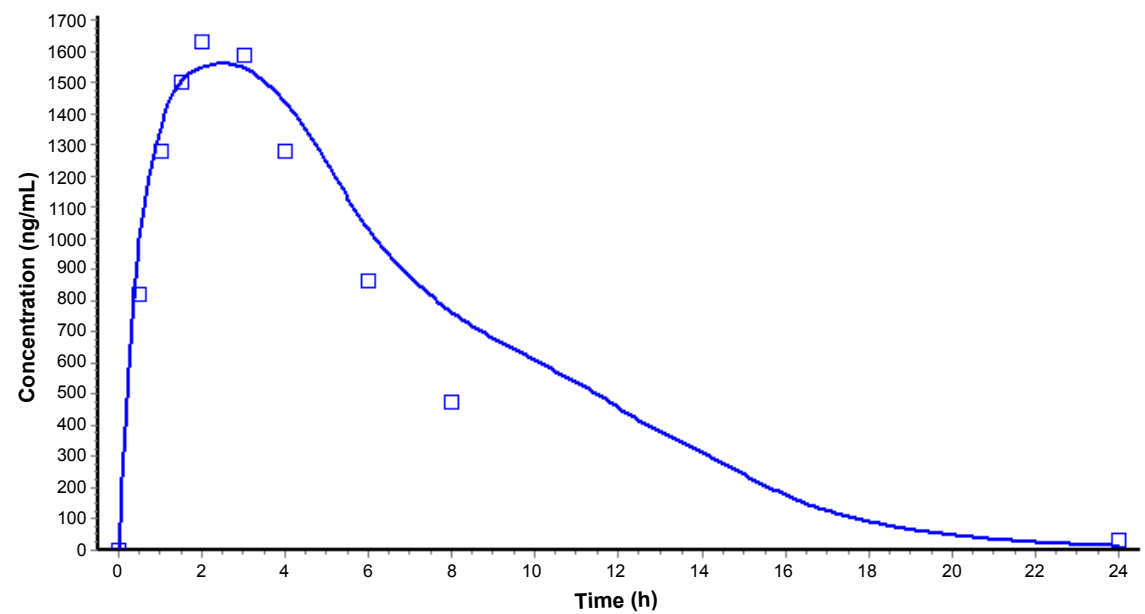

Figure 2: The observed (doted line) and the predicted (solid line) plasma concentration profile after oral administration of $1000 \mathrm{mg}$ of metformin in the control group.

\begin{tabular}{|c|c|c|c|}
\hline Condition & Parmeters & Predicted mean & Observed mean \\
\hline \multirow{4}{*}{ 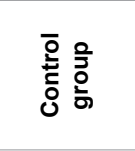 } & $\mathrm{C}_{\max }(\mathrm{ug} / \mathrm{h})$ & 1.59 & $1.8(0.61)$ \\
\hline & $\mathrm{T}_{\max }(\mathrm{hr})$ & 2.49 & $3.0(1.5-3.0)$ \\
\hline & AUC0-inf $h(u g / h / m L):$ & 13.70 & $11.4(3.6)$ \\
\hline & AUC0-24 h(ug/h/mL) & 13.59 & $11.1(3.6)$ \\
\hline \multirow{4}{*}{ 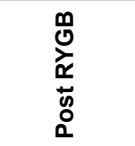 } & $\mathrm{C}_{\max }(\mathrm{ug} / \mathrm{h})$ & 2.3617 & $2.0(0.86)$ \\
\hline & $\mathrm{T}_{\max }(\mathrm{hr})$ & 1.4067 & $3.0(1.5-3.0)$ \\
\hline & AUC0-inf $h(u g / h / m L):$ & 15.82 & $13.7(6.0)$ \\
\hline & AUC0-24 h(ug/h/mL) & 15.75 & $13.4(5.7)$ \\
\hline
\end{tabular}

$\star$ Data are means (SD) based on the experimental sample size 15.

Table 5: The observed and predicted $\mathrm{C}_{\max }, \mathrm{T}_{\max }$ and AUC0-24 $\mathrm{h}$ after oral administration of 1000mg of metformin in the control and post RYGB (simulation resulted from model with increased the pore size, porosity and the absorptive surface area)

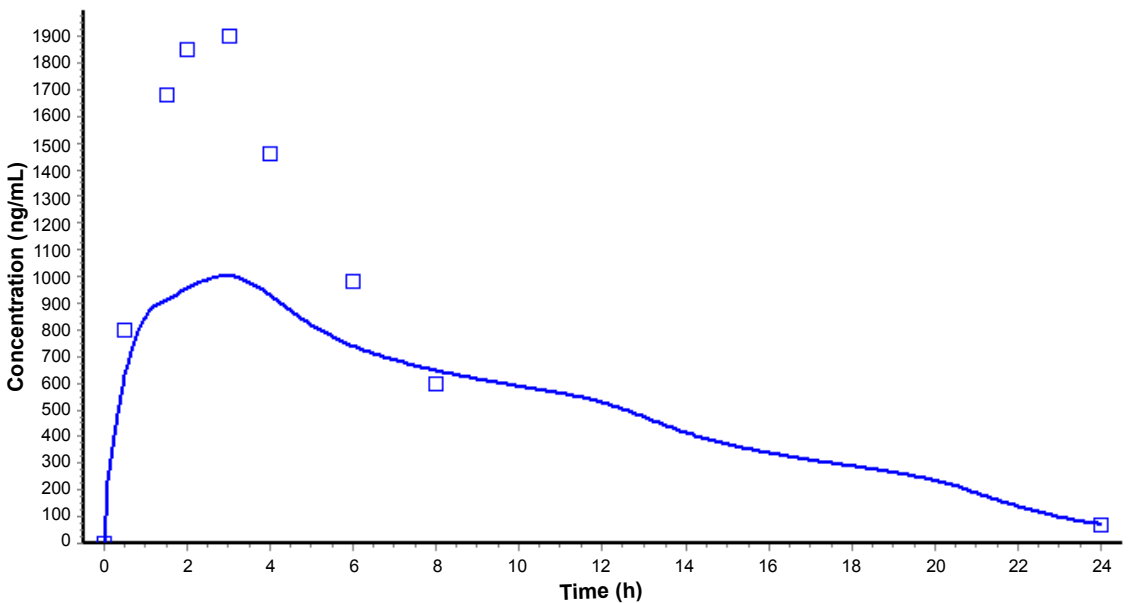

Figure 3: The observed (doted lines) and the predicted (solid line) plasma concentration profile after oral administration of $1000 \mathrm{mg}$ metformin in patients post RYGB. Simulation is based on intestinal model with simple removal of bypassed portions of small intestine.

Using the modified Gastric Release option did not predict observed data (data not shown). Increasing the distribution of the transporters in Gastroplus ${ }^{\mathrm{TM}}$ in the remaining part of small intestine also did not improve the prediction to the observed data (data not shown). However, increasing the pore size, porosity and the absorptive surface area in the remaining part of small intestine resulted in a close match of plasma drug concentration vs. time of simulation to the observed data (Figure 4). The result also showed a comparable result between the pharmacokinetics parameters of the experimental and predicted values (Table 5).

\section{Discussion and Conclusion}

Over the past years, studies have shown many applications of simulations in drug discovery, particularly, in predicting drug 


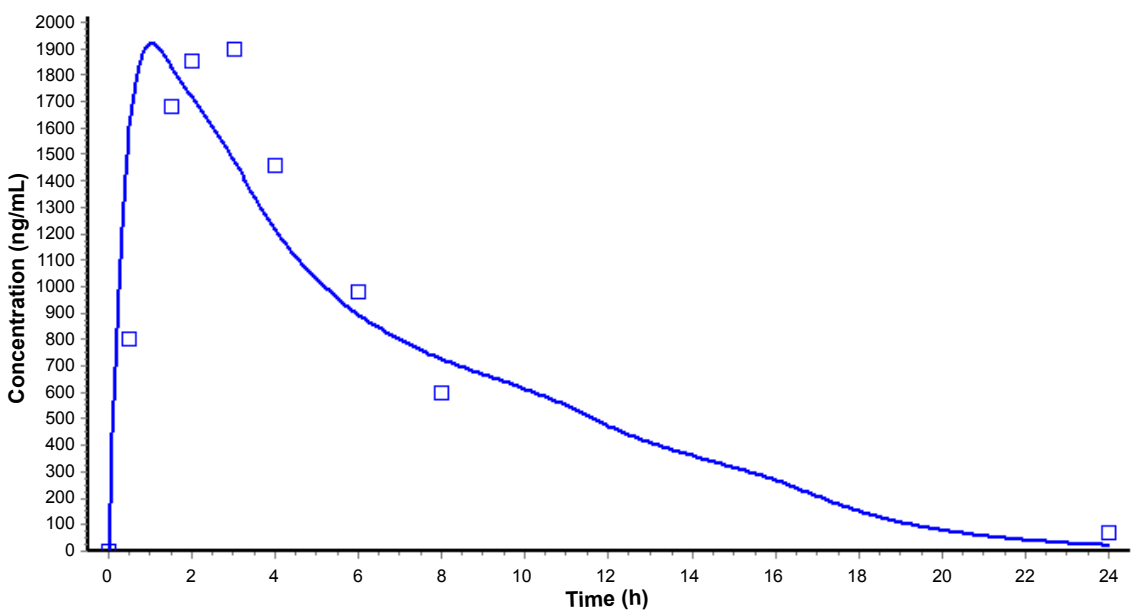

Figure 4: The observed (doted line) and the predicted (solid line) plasma concentration profile after oral administration of $1000 \mathrm{mg}$ metformin in patients post RYGB. Simulation resulted from model with increased the pore size, porosity and the absorptive surface area.

absorption. The usage of in silico model helped in understanding, identifying, and addressing many factors that affect the drug absorption and causes of observed absorption pattern. These factors range from the in vitro drug properties such as physiochemical characters of drugs to in vivo characteristics such as physiological properties of the GIT. Obesity surgery treatment changes the human GIT physiology, which is expected to have an influence on drug absorption. In this study, we have examined the application of simulations to understand the mechanistic changes in drug absorption in post RYGB subjects using metformin as a model drug. Metformin is an interesting model drug because the drug is highly soluble, but it is limited by its permeability. Studies reported that, in normal physiology, metformin is absorbed mainly in duodenum [12]. RYGB surgery is required bypassing the entire duodenum and a small portion of the proximal jejunum, therefore, reduced metformin absorption is anticipated. However, the observed published study showed the opposite: An increase in drug absorption [2]. In this study, computer simulations were used to test the ability of computer program to simulate the absorption after gastric bypass surgery and to test the theoretical assumptions that were reported to explain the observed drug absorption in such patients. This was done by altering the related values in the program inputs and comparing the predicted data with the observed ones. Then, to find out the most probable cause of the observed data, the assumption that could not predict the observed data was ruled out.

Appling only the controlled gastric release formulation in GastroPlus $^{\mathrm{TM}}$, could not predict the observed data, though this was actually not surprising. The Biopharmaceutical Classification System (BCS) classify drugs according to their solubility and permeability characteristics classified as Metformin as BCS class 3 drug [28]. Metformin is a highly soluble drug; therefore, retaining the drug in the stomach and releasing it slowly would not expected to significantly affect the drug absorption. However, such effects seem to have a significant effect for poorly soluble drugs as shown by AghazadehHabashi et al. for meloxicam [29]. This finding supported by a study conducted by Marathe et al., who studied the effect of the prolong gastric emptying and the gastrointestinal transient time induced by metcloprmide and propantheline on the metformin absorption on healthy volunteers [30]. The study was conducted in 11 healthy volunteers, who received $550 \mathrm{mg}$ metformin hydrochloride in solution alone; $5 \mathrm{~min}$ after a $10 \mathrm{mg}$ i.v. dose of metoclopramide; and $30 \mathrm{~min}$ after a $30 \mathrm{mg}$ oral dose of propantheline. Metformin solution was radiolabeled and then the gastrointestinal transit was T-monitored by gamma scintigraphy [30]. The study showed that the increase in the small intestinal transit times induced by propantheline cause a decline in metformin plasma concentrations associated with the colon arrival [30]. The study concluded that first part of small intestine is the main site of absorption of metformin Therefore, the prolonged in the GI transient time by RYGB could not explain the observation as the first part of small intestine is removed by surgery.

The result also showed that increasing in the transporters expression in the last part of the small intestine did not predict the observed data. As mentioned above, metformin is limited by its permeability. Studies showed that $90 \%$ of metformin is absorbed by paracellularly, which occurs via facilitated diffusion, and only $10 \%$ of the drug is absorbed transcellularly, which is mediated by transporters [12]. Therefore, the increase in the transporters expression is not expected to significantly increase the drug absorption. Moreover, studies showed that PMAT transporter, which a substrate for metformin absorption is sensitive to $\mathrm{pH}$ change. Studies showed a significant influence of acidic $\mathrm{pH}$ on PMAT in mediating metformin [13]. The study found that PMATmediated metformin uptake at $\mathrm{pH} 6.6$ is 4 fold higher than at $\mathrm{pH} 7.4$ [14]. However, the $\mathrm{pH}$ of the last part of the small intestine, which is the part lifted after the surgery, is higher than 6.6. In other words, PMAT activity expected to be decrease after RYGB surgery. These finding support the inability of the simulation of the up regulation the transporter in prediction of the observed metformin bioavailability after RYGB.

The last assumption that was used to explain the observation was an adaptation mechanism in the intestinal drug absorption. This assumption is supported by many studies in man and animals [31-34]. Studies have reported that obese patients, who had bypass surgery, were losing body weight after the surgery, but later the body weight will stabilize. Therefore, studies were conducted to explain this phenomenon. Interestingly, researchers found that patients who had obesity bypass surgery showed a clear evidence of adaptation. Studies have observed an increase in the intestinal epithelial surface area with an increase of the functional capacity of the intestine [31,34]. Miskowiak et al. [32] has measured the length of the small intestine in 
thirty-two patients after 6 to77 months of jejunoileal bypass surgery. The lengths were recorded 3 times by the same surgeon. Intestinal wall thickness was also measured for some patients. Miskowiak et al. found that the length of the small intestine was increased in patients with an association of unsatisfactory weight lost [32]. Stock-Damge et al. also supported this observation [33]. In his study, intestinal biopsy samples were obtained surgically from 41 obese patients subjected to a biliopancreatic bypass. The specimens were collected from the proximal and distal ileum, and colon. An image analyser determined the height of the mucosa, including villi and crypts. The study showed that the mucosa of the proximal and distal ileum showed a marked lengthening of the villi after biliopancreatic bypass. Inthe colon the biliopancreatic bypass induced, $40 \%$ of the patients' focal changes in the mucosa, characterized by the presence of true villi with mucous cells and epithelial cells [33]. In all other patients, the colonic mucosa was slightly thicker, but its morphologic aspect remained normal. The same observation was documented after RYGB in rat models [35]. The intestine showed an increased in villus height and crypt cell proliferation adaptation after 6-8 months of RYGBP surgery $[35,36]$. These results suggest that this observation was not limited to the type of bypass of surgery. Studies showed that there is a correlation between the length of intestine removed and the subsequent change in villus height in humans. Studies have referred these adaptations to a systemic hormonal stimulus [35]. Gastrin and enteroglucagon, particularly glucagon-like peptide 2 (GLP-2) have been proposed as primary cause of the adaptation $[33,37]$. Le Roux et al. determined the changes in GLP2 levels and crypt cell proliferation in rodents and in man after RYGB and the association between increased GLP- 2 concentrations and crypt cell proliferation in rodents after RYGB [38]. The study showed that in humans GLP-2 levels rise substantially after RYGB, peaking at 6 to 12 months, before returning to normal levels. This increase appears to be sufficient to maintain an increased small bowel mass following RYBG [38]. An interesting recent publish study has investigated the impact of RYGB on the permeability of small intestine [35,39] The study evaluated the intestine permeability by measuring the renal excretion rate of orally administered lactulose and mannitol and assessed the lactulose/mannitol ratio excretion rate in patients in three periods: before RYGB, one month after RYGB and 6 months after RYGB [39]. The study found a significant increase in mannitol excretion after RYGB surgery in addition to an increase in lactulose/mannitol ratio excretion [39]. The study concludes that patients after RYGB have an increase in the intestinal permeability by adaption mechanism [39]. As a matter of fact, this study substantiates our result because manitol is absorbed in vivo in a manner similar to metformin, through paracellular passive diffusion.

All of these studies supported the assumption behind the observed absorption of metformin. This mechanism is corresponds with the stabilizing in the weight loss and the decrease in surgery side effects such as diarrhea for a time- a period of the operation. However, one should remember that this does not mean that all drug absorption would be the same after bypass surgery. As mentioned above drug absorption is influenced by both, the GIT physiology and the drug physiochemical properties. Therefore, if a drug is limited by its permeability, class 3 drugs, and it is absorbed by passive diffusion with no active metabolise, the overall drug absorption is expected to be improving or show no change after RYGB due to adaption mechanism. Based on these data, the increased bioavailability of the drug, can improve clinical outcome and the pharmacodynamics action of Metformin in diabetic patients especially who undergo RYGB for more than 6 months. However, if the drug is limited by its solubility, i.e. class 2 drug, a change in the fraction dose absorbed is expected as the GI, $\mathrm{pH}$, and the transit time after bypass surgery have changed.

Computer simulation can be used to confirm this finding. Rowland et al. has reviewed the application of PBPK module to understand the variations in the observation of the drug absorption [40]. He reviewed many studies, which used PBPK module, to realize how physiological factors such as age, gender, race, weight, height, disease, genetic polymorphism, pregnancy, and organ impairments influence the PK of drugs that administered to each populations in these conditions [40]. One of recent study has also evaluated using PBPK modeling, using the Simcyp Simulator ${ }^{\mathrm{TM}}$ software, as a tool in examining the impact of physiological changes in obesity surgery [4]. The study used cyclosporine and atorvastatin as models drugs to predict the drugs absorption after RYBG and biliopancreatic diversion biliopancreatic diversion with duodenal switch, respectively. The study concluded that PBPK has a potential to predict the oral drug bioavailability in the absence of clinical data [4]. The current study supports this finding and showed the importance of using computer simulations as a valuable tool to simulate the impact and mechanistic background of the physiological changes on drugs absorption. The insights gained by this study can be used to help to predict the absorption and the clinical outcomes of other drugs that have similar physiochemical properties like metformin after RYBG.

\section{Acknowledgment}

The authors would like to thank Simulation Plus, and Princess Nora Bint Abdulrahman University for their support

\section{References}

1. Sarwer DB, Faulconbridge LF, Steffen KJ, Roerig JL, Mitchell JE (2011) Managing patients after surgery: Changes in the gastrointestinal tract and body weight can alter drug absorption. Current Psychiatry 10: 18-30.

2. Padwal RS, Gabr RQ, Sharma AM, Langkaas LA, Birch DW, et al. (2011) Effect of gastric bypass surgery on the absorption and bioavailability of metformin Diabetes Care 34: 1295-1300.

3. Smith BR, Schauer P, Nguyen NT (2011) Surgical approaches to the treatment of obesity: bariatric surgery. Med Clin North Am 95: 1009-1030.

4. Darwich AS, Pade D, Rowland-Yeo K, Jamei M, Asberg A, et al. (2013) Evaluation of an In Silico PBPK Post-Bariatric Surgery Model through Simulating Oral Drug Bioavailability of Atorvastatin and Cyclosporine. CPT Pharmacometrics Syst Pharmacol 2: e47.

5. Rouabhia S, Milic N, Abenavoli L (2014) Metformin in the treatment of nonalcoholic fatty liver disease: safety, efficacy and mechanism. Expert Rev Gastroenterol Hepatol.

6. Agoram B, Woltosz WS, Bolger MB (2001) Predicting the impact of physiologica and biochemical processes on oral drug bioavailability. Adv Drug Deliv Rev 50: S41-67.

7. Yu LX, Amidon GL (1998) Characterization of small intestinal transit time distribution in humans. Int J Pharm 171: 157-163.

8. Roux-en-Y gastric bypass [Internet]: wikipedia; 8 October 2013; cited 29 March 2014].

9. Pentikäinen PJ, Neuvonen PJ, Penttilä A (1979) Pharmacokinetics of metformin after intravenous and oral administration to man. Eur J Clin Pharmacol 16: 195202

10. Wang G, Agenor K, Pizot J, Kotler DP, Harel Y, et al. (2012) Accelerated gastric emptying but no carbohydrate malabsorption 1 year after gastric bypass surgery (GBP). Obes Surg 22: 1263-1267.

11. Wang DS, Jonker JW, Kato $Y$, Kusuhara $H$, Schinkel AH, et al. (2002) Involvement of organic cation transporter 1 in hepatic and intestinal distribution of metformin. J Pharmacol Exp Ther 302: 510-515.

12. Proctor WR, Bourdet DL, Thakker DR (2008) Mechanisms underlying saturable intestinal absorption of metformin. Drug Metab Dispos 36: 1650-1658. 
Citation: Almukainzi M, Lukacova V, Löbenberg R (2014) Modelling the Absorption of Metformin with Patients Post Gastric Bypass Surgery. J Diabetes Metab 5: 353 doi:10.4172/2155-6156.1000353

13. Zhou M, Xia L, Wang J (2007) Metformin transport by a newly cloned proton-stimulated organic cation transporter (plasma membrane monoamine transporter) expressed in human intestine. Drug Metab Dispos 35: 1956-1962.

14. Xia L, Engel K, Zhou M, Wang J (2007) Membrane localization and pHdependent transport of a newly cloned organic cation transporter (PMAT) in kidney cells. Am J Physiol Renal Physiol 292: F682-690.

15. Ito S, Kusuhara H, Yokochi M, Toyoshima J, Inoue K, et al. (2012) Competitive inhibition of the luminal efflux by multidrug and toxin extrusions, but not basolateral uptake by organic cation transporter 2 , is the likely mechanism underlying the pharmacokinetic drug-drug interactions caused by cimetidine in the kidney. J Pharmacol Exp Ther 340: 393-403.

16. Tanihara Y, Masuda S, Sato T, Katsura T, Ogawa O, et al. (2007) Substrate specificity of MATE1 and MATE2-K, human multidrug and toxin extrusions/ $\mathrm{H}(+)$-organic cation antiporters. Biochem Pharmacol 74: 359-371.

17. Kimura N, Masuda S, Tanihara Y, Ueo H, Okuda M, et al. (2005) Metformin is a superior substrate for renal organic cation transporter OCT2 rather than hepatic OCT1. Drug Metab Pharmacokinet 20: 379-386.

18. Zhimin H (1995) Transactions of Tianjin University 1: 42-47.

19. Johnson W, DeMaria E (2006) Surgical treatment of obesity. Curr Treat Options Gastroenterol 9: 167-174.

20. Miller AD, Smith KM (2006) Medication and nutrient administration considerations after bariatric surgery. Am J Health Syst Pharm 63: 1852-1857.

21. Malone M (2003) Altered drug disposition in obesity and after bariatric surgery Nutr Clin Pract 18: 131-135.

22. Chambers AP, Smith EP, Begg DP, Grayson BE, Sisley S, et al. (2014) Regulation of gastric emptying rate and its role in nutrient-induced GLP-1 secretion in rats after vertical sleeve gastrectomy. Am J Physiol Endocrinol Metab 306: E424-432.

23. Horner KM, Byrne NM, Cleghorn GJ, Näslund E, King NA (2011) The effects of weight loss strategies on gastric emptying and appetite control. Obes Rev 12: $935-951$.

24. Suzuki S1, Ramos EJ, Goncalves CG, Chen C, Meguid MM (2005) Changes in GI hormones and their effect on gastric emptying and transit times after Rouxen-Y gastric bypass in rat model. Surgery 138: 283-290.

25. Padwal R, Brocks D, Sharma AM (2010) A systematic review of drug absorption following bariatric surgery and its theoretical implications. Obes Rev 11: 41-50.

26. Tappenden KA (2014) Intestinal adaptation following resection. J Parenter Enteral Nutr
27. Quigley EM, Thompson JS (1993) The motor response to intestinal resection: motor activity in the canine small intestine following distal resection. Gastroenterology 105: 791-798.

28. Mathias NR, Crison $\mathrm{J}$ (2012) The use of modeling tools to drive efficient ora product design. AAPS J 14: 591-600.

29. Aghazadeh-Habashi A, Jamali F (2008) Pharmacokinetics of meloxicam administered as regular and fast dissolving formulations to the rat: Influence of gastrointestinal dysfunction on the relative bioavailability of two formulations. Eur J Pharm Biopharm 70: 889-894.

30. Marathe PH, Wen Y, Norton J, Greene DS, Barbhaiya RH, et al. (2000) Effect of altered gastric emptying and gastrointestinal motility on metformin absorption. Br J Clin Pharmacol 50: 325-332.

31. Solhaug JH (1976) Morphometric studies of the small intestine following jejunoileal shunt operation. Scand J Gastroenterol 11: 155-160.

32. Miskowiak J, Andersen B (1983) Intestinal adaptation after jejunoileal bypass for morbid obesity: a possible explanation for inadequate weight loss. Br J Surg 70: $27-28$

33. Stock-Damgé C, Aprahamian M, Raul F, Marescaux J, Scopinaro N (1986) Small-intestinal and colonic changes after biliopancreatic bypass for morbid obesity. Scand J Gastroenterol 21: 1115-1123.

34. Doldi SB (1991) Intestinal adaptation following jejuno-ileal bypass. Clin Nutr 10: $138-145$

35. Shaw D, Gohil K, Basson MD (2012) Intestinal mucosal atrophy and adaptation World J Gastroenterol 18: 6357-6375.

36. Spak E, Björklund P, Helander HF, Vieth M, Olbers T, et al. (2010) Changes in the mucosa of the Roux-limb after gastric bypass surgery. Histopathology 57 $680-688$.

37. Barry RE, Barisch J, Bray GA, Sperling MA, Morin RJ, et al. (1977) Intestinal adaptation after jejunoileal bypass in man. Am J Clin Nutr 30: 32-42.

38. le Roux CW, Borg C, Wallis K, Vincent RP, Bueter M, et al. (2010) Gut hypertrophy after gastric bypass is associated with increased glucagon-like peptide 2 and intestinal crypt cell proliferation. Ann Surg 252: 50-56.

39. Savassi-Rocha AL, Diniz MT, Vilela EG, Diniz Mde F, Sanches SR, et al. (2014) Changes in intestinal permeability after Roux-en-Y gastric bypass. Obes Surg 24: $184-190$.

40. Rowland M, Peck C, Tucker G (2011) Physiologically-based pharmacokinetics in drug development and regulatory science. Annu Rev Pharmacol Toxicol 51 $45-73$ 